\title{
$\sin x=$

\section{PENGARUH DISIPLIN KERJA TERHADAP KINERJA KARYAWAN DI THE PREMIER BASKO HOTEL PADANG}

\author{
Nopi Acel, Youmil Abrian \\ Program Studi D4 Manajemen Perhotelan \\ Jurusan Pariwisata \\ Fakultas Pariwisata dan Perhotelan Universitas Negeri Padang \\ E-mail: nopiacel1808@gmail.com
}

\begin{abstract}
The purpose of this study was to determine the effect of work discipline on employee performance at The Premier Basko Hotel Padang. This type of reseativerch is quantitatitive descriptive with causal assumptions. The sample uses saturated sample technique with 51 people using a questionnaire with a Likert scale. The results showed: (1) Work Disclipine for the very bad category(39,2\%), (2) Employee performance in the low category (3,92\%), (3) Simple linear regression test value obtained $F 461,001$ with the value 0.000 signifiance $<0.05$, so work discipline can be said to be significant, With $R$ Square value of 0,88. This means that employee perfomance is influenced by work discipline as much as $8,8 \%$ and $91,2 \%$ is influenced by other factors. Then obtained regression coefficient value of 1.568 significance $0.000<0.05$. This means that each addition of 1 unit of work discipline will add 1,568 employee perfomance.
\end{abstract}

Key word: Discipline, Perfomance, Employees

\section{PENDAHULUAN}

Hotel adalah Suatu perusahaan yang dikelola oleh pemiliknya dengan menyediakan pelayanan makanan,minuman dan fasilitas kamar untuk tidur kepada orang-orang yang sedang melakukan perjalanan dan mampu membayar dengan jumlah yang wajar sesuai dengan pelayanan yang diterima tanpa adanya perjanjian khusus, Menurut Sulastiyono (2001:5).Salah satunya Hotel Yng berbintang 4 di kota padang adalah The Premier Basko Hotel Padang

Kinerja Karyawan merupakan salah satu dimensi yang dapat digunakan untuk mengukur, mengevaluasi kekuatan karyawan dalam bertahan serta melaksanakan tugas dan kewajibannya terhadap organisasi dimana ia bernaung.menurut Nawawi dalam nora cetisia (2017: 3) indikator kinerja yaitu "kualitas, kuantitas, ketepatan waktu, kerja sama antar karyawan dan kehadiran". Malasah yang ditemui mengenai kinerja karyawan di The premier Basko Hotel Padang adalah adanya karyawan yang tidak bisa menyelesaikan pekerjaan yang dibebankan kepadanya seperti, tidak tercapainya target pembersihan kamar oleh roomboy, sehingga pekerjaan tersebut harus dilakukan oleh shift selanjutnya. Hal ini berdampak penjualan kamar yang kurang maksimal karena sebagian tamu berasal dari walk in guest atau tamu yang check in tanpa melakukan resevasi sebelumnya.

Disiplin Kerja adalah suatu sikap, tingkah laku dan perbuatan yang sesuai dengan peraturan dari perusahaan baik yang tertulis maupun tidak tertulis, dalam disiplin kerja yang menjadi faktor pokok adalah adanya kesadaran dan keinsafan terhadap aturan-aturan yang berlaku dalam perusahaan. Disiplin kerja sangat penting dalam usaha untuk menjamin 
terpeliharanya tata tertib serta pelaksanaan setiap tugas.

Kesalahan lain yang juga kerap terjadi di hotel adalah Sebagian karyawan menundanunda menyelesaikan pekerjaan yang seharusnya bisa diselesaikan tepat waktu contohnya kelalaian yang dilakukan oleh staff banquet

Berdasarkan uraian di atas maka penulis tertarik untuk meneliti lebih lanjut apakah terdapat pengaruh antara disilpin kerja terhadap kinerja karyawan di The Premier Basko Hotel Padang dengan judul: "Pengaruh Disiplin Kerja terhadap Kinerja Karyawan di The Premier Basko Hotel Padang”.

\section{METODE}

Penelitian ini digolongkan kepada penelitian deskriptif kuantitatif yaitu dengan metode asosiatif bentuk hubungan kausal, dengan jumlah sampel 51 orang. Metode yang diguankan adalah teknik propotional random sampling. Dengan koresponden seluruh karyawan di the premier basko hotel padang. Pengumpulan data melalui angket, dengan bantuan skala likert. Teknik analisis penelitian ini menggunakan analisis regresi liniear sederhana.

Seterusnya uji persyaratan analisisnya adalah uji normalitas, homogenitas, linearlitas serta pengujian hipotesis menggunakan regresi linear sederhana untuk melihat besaran pengaruh disiplin kerja terhadap variabel kinerja karyawan.

\section{HASIL DAN PEMBAHASAN}

\section{Hasil Penelitian}

\section{a.Analisis Deskriptif}

Berikut hasil penelitian tentang disiplin kerja di kategorikan pada tabel berikut:
Tabel 1. Distribusi Frekuensi Variabel $\mathrm{X}$ (Disiplin Kerja)

\begin{tabular}{|c|l|c|c|}
\hline Kategori & \multicolumn{1}{|c|}{ Skor } & F & Persentase(\%) \\
\hline SangatBaik & $>91,95$ & 20 & 39,2 \\
\hline \multirow{2}{*}{ Baik } & $\begin{array}{l}>76,65-< \\
91,95\end{array}$ & 13 & 25,5 \\
\hline \multirow{2}{*}{ Cukup } & $\begin{array}{l}>61,35-< \\
76,65\end{array}$ & 14 & 27,4 \\
\hline \multirow{2}{*}{ Buruk } & $\begin{array}{l}746,05-< \\
61,35\end{array}$ & 4 & 7,9 \\
\hline SangatBuruk & $<46,05$ & 0 & 0 \\
\hline \multicolumn{2}{|c|}{ Total } & 51 & 100 \\
\hline
\end{tabular}

Sumber : Data Primer 2018

Berdasarkan pada table di atas dilihat bahwa $39,2 \%$ responden berpendapat bahwa disiplin kerja sangat baik, 25,5\% menyatakan baik, dan $27,4 \%$ responden menyatakan cukup.

Tabel 2. Data hasil kinerja karyawan The Premier Basko Hotel Padang Variabel Y (Kinerja Karyawan)

\begin{tabular}{|c|c|c|}
\hline Kinerja & Jumlah & Persentase \\
\hline Sangat Baik & 10 & $(19,7 \%)$ \\
\hline Baik & 39 & $(76,4 \%)$ \\
\hline Cukup & 2 & $(3,9 \%)$ \\
\hline Buruk & 0 & $(0 \%)$ \\
\hline Sangat Buruk & 0 & $(0 \%)$ \\
\hline
\end{tabular}

Sumber: Data Sekunder HRD The Premier

\section{Basko Hotel Padang, 2018}

Berdasarkan pada table di atas dilihat bahwa $19,7 \%$ responden berpendapat bahwa kinerja karyawan sangat baik, 76,4\% menyatakan baik, dan $3,9 \%$ responden menyatakan cukup.

\section{b. Persyaratan Analisis}

\section{1) Uji Normalitas}

Dengan hasil uji normalitas mengenai disiplin kerja dan kinerja karyawan dapat dikategorikan pada table di bawah ini 
Tabel 3. Hasil Uji Normalitas One-Sample Kolmogorov-Smirnov Test

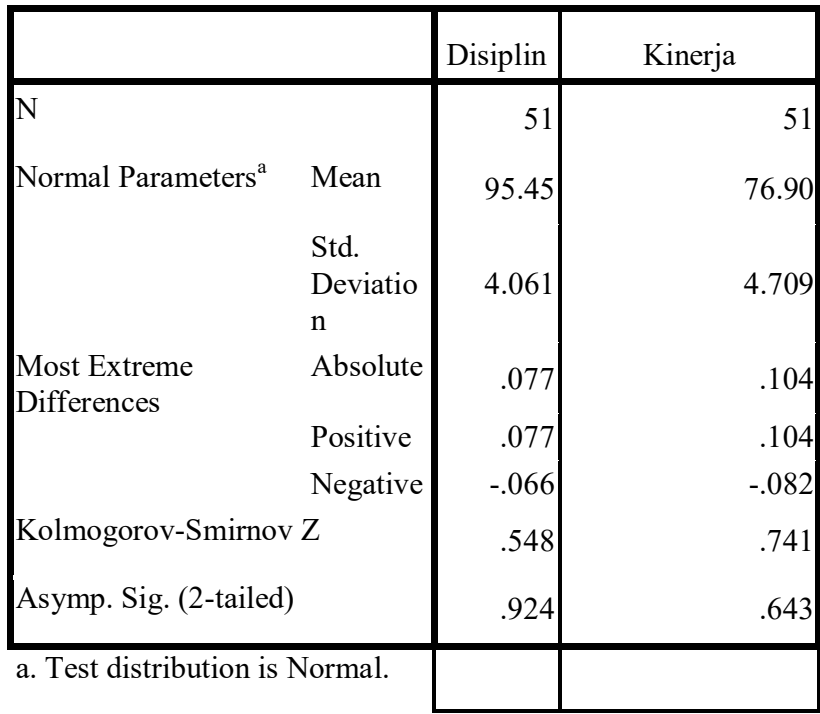

Dapat kita lihat nilai Asymp. Sig variabel disiplin kerja adalah 924, variabel kinerja karyawan adalah 643. Nilai signifikansi $>0,05$ dan di nyatakan data tersebut normal.

1) Uji Homogenitas

Dari hasil uji homogenitas mengenai disiplin kerja, dan kinerja karyawan dapat dikategorikan pada table dibawah:

Tabel 4. Hasil uji homogenitias

Test of Homogeneity of Variances

\begin{tabular}{|r|r|r|r|}
\hline Levene Statistic & \multicolumn{1}{|c|}{ df1 } & df2 & \multicolumn{1}{c|}{ Sig. } \\
\hline 3.231 & 9 & 34 & .006 \\
\hline
\end{tabular}

Uji homogenitas memiliki nilai signifikansi 0,06 $\geq 0,05$. Artinya data bersifat homogeny dan berasal dari populasi yang sama.

\section{1) Uji Linearitas}

Uji linearitas mengenai disiplin kerja, dan kinerja karyawan dapat dikategorikan pada table berikut:
Tabl 5. Hasil Uji Linearitas

\begin{tabular}{|c|c|c|c|c|c|c|c|}
\hline & & & $\begin{array}{l}\text { Sum of } \\
\text { Squares }\end{array}$ & $\mathrm{Df}$ & $\begin{array}{c}\text { Mea } \\
\mathrm{n} \\
\text { Squa } \\
\text { re }\end{array}$ & $\mathrm{F}$ & Sig. \\
\hline $\begin{array}{l}\text { Kinerj } \\
\text { a* } \\
\text { Disipl } \\
\text { in }\end{array}$ & $\begin{array}{l} \\
\text { Within } \\
\text { Groups } \\
\text { Total }\end{array}$ & $\begin{array}{l}\text { (Com } \\
\text { bined) } \\
\text { Linear } \\
\text { ity } \\
\text { Deviat } \\
\text { ion } \\
\text { from } \\
\text { Linear } \\
\text { ity }\end{array}$ & $\begin{array}{r}325.474 \\
.320 \\
325.154 \\
\\
783.036 \\
1108.51 \\
0\end{array}$ & $\begin{array}{l}34 \\
50\end{array}$ & \begin{tabular}{|r|}
20.3 \\
42 \\
\\
.320 \\
\\
\\
21.6 \\
77 \\
\\
\\
23.0 \\
30
\end{tabular} & $\begin{array}{l}.883 \\
.014 \\
.014\end{array}$ & $\begin{array}{l}.002 \\
.000\end{array}$ \\
\hline
\end{tabular}

Nilai uji linearitas dengan nilai signifikansi $0,532>0,05$, artinya ada hubungan linear antara variabel Disiplin kerja dan Kinerja karyawan.

\section{a.Pengujian hipotesis}

Hasil uji anova di atas diperoleh nilai $\mathrm{F}$ hitung 461.001 dengan taraf signifikansi $0,00<0,05$, dengan artian $\mathrm{Ha}$ diterima. Kesimpulannya disiplin kerja memiliki berpengaruh terhadap kinerja karyawan. 


\section{Tabel 6. Regresi Linear Sederhana}

\begin{tabular}{|c|c|c|c|c|c|}
\hline \multicolumn{6}{|c|}{ ANOVA $^{b}$} \\
\hline Model & $\begin{array}{c}\text { Sum } \\
\text { of } \\
\text { Square } \\
\text { s }\end{array}$ & $\begin{array}{l}\text { D } \\
\text { f }\end{array}$ & $\begin{array}{l}\text { Mean } \\
\text { Square }\end{array}$ & $\mathrm{F}$ & Sig \\
\hline $\begin{array}{l}1 \text { Regress } \\
\text { ion }\end{array}$ & $\begin{array}{r}17556 . \\
641\end{array}$ & 1 & $\begin{array}{r}17556 . \\
641\end{array}$ & $\begin{array}{r}461 \\
.00 \\
1\end{array}$ & $\begin{array}{r}.00 \\
0^{\mathrm{a}}\end{array}$ \\
\hline $\begin{array}{l}\text { Residua } \\
1 \\
\text { Total }\end{array}$ & $\begin{array}{r}1904.1 \\
86 \\
19460 . \\
827\end{array}$ & $\begin{array}{l}5 \\
0 \\
5 \\
1\end{array}$ & 38.084 & & \\
\hline
\end{tabular}

Sumber: Data Primer, 2018

Tabel 7. Hasil Uji Koefisien Regresi Variabel X Terhadap Y

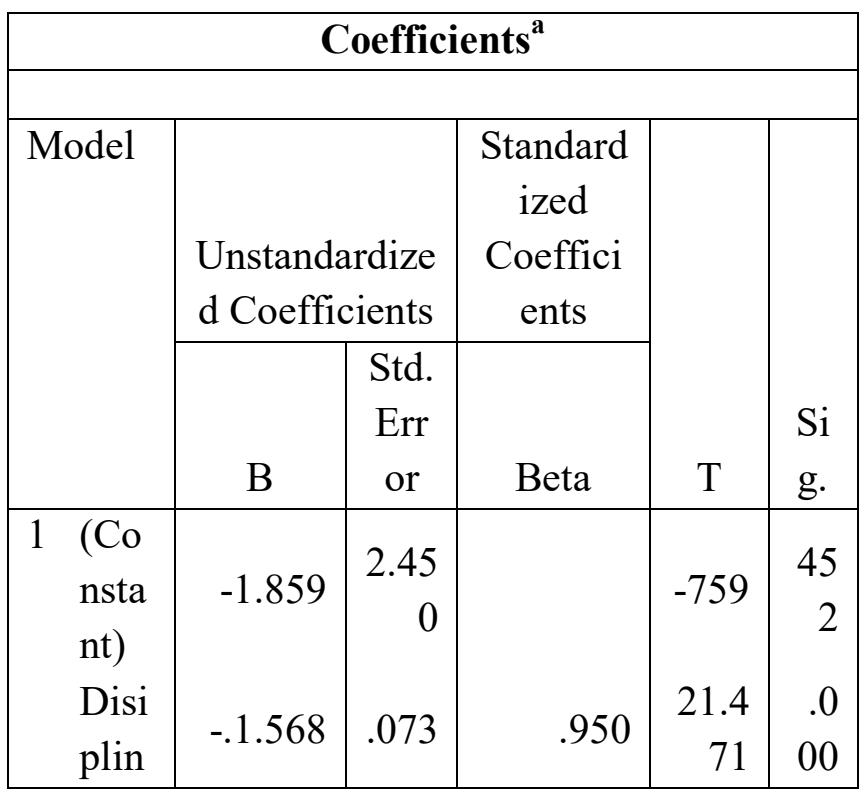

Sumber: Data Primer, 2018

Tabel tersebut menghasilkan persamaan regresinya yaitu :

\section{$Y=a+B=-1,859+1,568 X$}

Berdasarkan table diatas diperoleh nilai t sebesar 21,471 dengan taraf Sig 0,000, artinya variabel disiplin kerja $(\mathrm{X})$ mempunyai pengaruh yang signifikan terhadap kinerja karyawan (Y). Selanjutnya diperoleh koefisien regresi 1,568 dengan sig $0,000<0,005$ artinya setiap peningkatan 1 satuan disiplin kerja akan meningkatkan 1,568 satuan kinerja karyawan.

\section{Pembahasan}

Berdasarkan hasil uji hipotesis yang digunakan untuk mengetahui derajat pengaruh antara disiplin kerja terhadap kinerja karyawan di the premier basko hotel padang. Analisis dilakukan dengan bantuan SPSS 16.00 di peroleh Nilai $F_{\text {hitung }} 461.001$ dengan taraf signifikansi $0,00<0,05$ yang berarti disiplin kerja berpengaruh terhadap Kinerja karyawan. Demikian juga nilai koefisien regresi 8,8\% dengan nilai signifikansi $0,00<0,05$, diartikan setiap peningkatan 1 satuan pengembangan karir akan meningkatkan 8,8\% kinerja karyawan.

Kemudian diperoleh nilai $\mathrm{R}$ Square 0,88 Artinya pengaruh variabel $\mathrm{X}$ terhadap variabel $\mathrm{Y}$ adalah sebesar $0,88 \quad(8,8 \%)$. Sedangkan 91,2\% dipengaruhi oleh faktor lain. Maka hipotesis yang diterima dalam penelitian ini adalah $\mathrm{Ha}$ diterima dan Ho ditolak, dengan demikian disiplin kerja memiliki pengaruh yang signifikan terhdap kinerja karyawaan sebesar 8,8\% karena indikator dari disiplin kerja merupakan salah satu faktor internal yang dapat mempengaruhi kinerja karyawan sehingga dapat dikatakan semakin tinggi kedisiplinan kerja dari karyawan maka akan menigkatkan kinerja yang dihasilkan karyawan di the premier basko hotel padang. 
Menurut Anwar prabu (2009: 67), adalah "hasil kerja secara kualitas dan kuantitas yang dicapai oleh seorang pegawai dalam melaksanakan tugasnya sesuai dengan tanggung jawab yang diberikan kepadanya. faktor-faktor yang mempengaruhi kinerja karyawan meliputi: pendidikan, keterampilan, disiplin, sikap dan etika kerja, motivasi, gaji, kesehatan, teknologi, manajemen, dan kesempatan berprestasiinternal dan eksternal akan memberikan pengaruh terhadap kinerja karyawanMenurut Ravianto dalam Nora Cristilia (2017: 12).Disiplin kerja berpengaruh cukup besar terhadap kinerja karyawan, dan terdapat juga faktor lain yang dapat mempengaruhi kinerja karyawan seperti motivasi kerja, etika kerja, kompensasi dan lainnya.

Berdasarkan hasil penelitian tersebut dapat disimpulkan bahwa pengaruh disiplin kerja terhadap kinerja karyawan di the premier basko hotel padang berpengaruh secara signifikan. Disiplin kerja berpengaruh cukup besar terhadap kinerja karyawan, dan terdapat juga faktor lain yang dapat mempengaruhi kinerja karyawan seperti motivasi kerja, etika kerja, kompensasi dan lainnya.

\section{PENUTUP}

\section{Kesimpulan}

a. Tanggapan responden tentang Disiplin Kerja di The Premier Basko Hotel Padang menunjukkan secara keseluruhan pada kategori baik yaitu sebesar (39,2\%).

b. Hasil penilaian tentang Kinerja Karyawan di The Premier Basko Hotel Padang menunjukkan secara keseluruhan termasuk dalam kategori baik yaitu sebesar (96\%).

c. Pengaruh Disiplin Kerja Terhadap Kinerja Karyawan Di The Premier Basko Hotel Padang dengan persentase 8,8\% dan 91,2\% dipengaruhi oleh faktor lain.

\section{Saran}

Bagi pihak hotel diharapkan dapat mempertahankan dan meningkatkan program program ataupun disiplin yang telah diberikan kepada karyawan. Beserta faktor lain yang dapat mempengaruhi kinerja karyawan selain disiplin kerja, seperti kuantitas dan kualitas karyawan dalam bekerja agar lebih baik,

\section{DAFTAR PUSTAKA}

Agus Sulastiyono. 2001. Menejemen Penyelenggaraan Hotel, C.V.Alfabeta, Bandung. Dinas Pariwisata Kota Bandung

Anwar, Prabu Mangkunegara. 2009. Manajemen Sumber Daya Manusia Bandung: RemajaRosdakarya.

Nawawi, Hadari. 2006. Evaluasi dan manajemen Kinerja di Lingkungan Perusahaan dan Industri. Yogyakarta: Gajah Mada Univercity Press.

Nora Cetisia, Waryono \& Youmil Abrian. 2017. "PENGARUH DISIPLIN KERJA TERHADAP KINERJA KARYAWAN DI HOTEL GRAND ROCKY BUKITTINGGI". E-Jounal Home Econimic and Tourism, vol 15 no. 